\title{
The effect of size on the mechanical properties of the myotomal-skeletal system of rainbow trout (Salmo gairdneri)
}

\author{
P.W. Webb and C.L. Johnsrude* \\ Department of Biology and School of Natural Resources, The University of Michigan, Ann Arbor, \\ MI 48109-1115, USA
}

Keywords: rainbow trout, myotome, muscle, acceleration, swimming

\begin{abstract}
The length and mean cross-sectional area of the myotome of rainbow trout, Salmo gairdneri, scale isometrically with total length $(\mathrm{L}, \mathrm{cm})$ and $\mathrm{L}^{2}$ respectively for fish from 5 to $35 \mathrm{~cm}$ in length. The net maximum force, $\left(\mathrm{F}, \mathrm{kN} \cdot \mathrm{m}^{-2}\right)$ developed by a single twitch of the in situ myotome on one side of the body, and measured normal to the hypural complex increased as; $F=1.05 \times 10^{-3} \cdot \mathrm{L}^{2.6}$, and maximum lateral velocity $\left(\mathrm{W}, \mathrm{m} \cdot \mathrm{s}^{-1}\right)$ at the hypural plate as; $\mathrm{W}=0.29 \mathrm{~L}^{-0.47}$. Maximum power $(\mathrm{P}, \mathrm{W})$ increased as; $\mathrm{P}=7.64 \times$ $10^{-5} \cdot \mathrm{L}^{3.06}$. Acceleration rates predicted from these data do not agree well with observations. In addition, except for small fish, predicted maximum speeds differed from those calculated from minimum twitch times of excised muscle blocks and stride length, the popular method for estimating maximum speed. It is suggested that temporal summation of twitches must occur in larger fish. This could provide forces matched to inertial loads which are important in fitness-critical maneuvers.
\end{abstract}

\section{Introduction}

Relationships of size with metabolism, swimming performance, and kinematics have been determined for fish at sustainable or prolonged activity levels (Bainbridge 1958, 1962; Brett 1965; Brett and Glass 1973; Webb et al. 1984) and fast starts (Webb 1976), although only for relatively small fish (Wardle 1977). Maximum sprint speeds remain unknown with certainty for any species, largely because measurement of such speeds is technically difficult, especially for large fish. Indeed, a suitable conceptual framework, and hence techniques and methodologies are lacking for direct measurement of maximum speed. Nevertheless, knowledge of the maximum sprint speeds is sought because of its relevance to understanding functional morphology of fish, and because this information is believed desirable for setting maximum flow velocities in designing stream constrictions.

Because of the difficulties of direct observation, estimation of performance limits from measurable muscle performance parameters is attractive. Swimming performance and scaling relationships have been inferred from theory coupled with assumptions on muscle performance (Bainbridge 1961; Wardle 1977), and measurements on blocks of fish muscle (Wardle 1975) or fibers (Moerland and Sidell 1986). However, results from such studies are difficult to extrapolate to whole animal performance because of the complex geometry of the fast glycolyic fiber portion of the myotome (Wain-

* Present address: School of Medicine, East Carolina University, Greenvile, NC 27858. 
wright 1983). Johnsrude and Webb (1985) attempted to overcome this problem by measuring the properties of a preparation of the myotomal muscle in situ. The research reported here examines the effect of size on the properties of this myotomalskeletal system and further evaluates the utility of muscle preparations for predicting maximum swimming performance.

\section{Materials and methods}

Fish

Nineteen rainbow trout (Salmo gairdneri) were used from laboratory stocks. Fish were obtained from a local hatchery, and acclimated to the laboratory at $15^{\circ} \mathrm{C}$ for at least three weeks. Fish were kept in 200-liter oval tanks, continuously flushed with water, and containing an air stone to maintain dissolved oxygen concentrations close to air saturation. Fish were fed a maintenance ration of Purina trout chow.

\section{Procedure}

The methods used are described in detail by Johnsrude, and Webb (1985). Briefly, fish were carefully netted with minimal chasing and quickly ( $<1 \mathrm{sec}$ ) immersed in water containing 1:10,000 MS222 (tricaine methanesulphonate). Once breathing movements had stopped, total fish length and mass were measured. These ranged from 5 to $35 \mathrm{~cm}$ in length, and 1.55 to $420 \mathrm{~g}$ in mass (Table 1 ).

The entire myotomal muscle was removed from one side of the body. The remaining half-myotome preparation, with all skeletal elements intact, was mounted with the vertebral column down on a solid horizontal planar surface. Results from this posture are typical of performance for the myotome in all positions seen in normal swimming (Johnsrude and Webb 1985). The head (nose to cleithrum) was clamped firmly to the surface. An inelastic thread was attached to the hypural complex and passed through a slit in the surface to a low-mass beam oriented parallel to the caudal fin. Intramuscular
Table l. Regression equations for morphometrics of trout used in the experiments.

\begin{tabular}{|c|c|c|}
\hline & Equations & $r^{2}$ \\
\hline $\begin{array}{l}\text { Mass } \\
\qquad(\mathrm{M}, \mathrm{g})\end{array}$ & $\begin{aligned} M & =0.011 L^{2.961=0.02)} \\
& ( \pm 0.001)\end{aligned}$ & 0.997 \\
\hline $\begin{array}{l}\text { Cross-sectional area of } \\
\text { muscle }\left(\mathrm{A}, \mathrm{cm}^{2}\right)\end{array}$ & $\begin{aligned} A & =0.011\lfloor 1.791=0.04) \\
& ( \pm 0.001)\end{aligned}$ & 0.991 \\
\hline $\begin{array}{l}\text { Muscle mass } \\
\qquad\left(\mathrm{M}_{\mathrm{m}}, \mathrm{g}\right)\end{array}$ & $\begin{aligned} M_{m} & \left.=0.003 L^{3}+1+1 \div 0.081\right) \\
& ( \pm 0.001)\end{aligned}$ & 0.996 \\
\hline $\begin{array}{l}\text { Length of myotome } \\
\left.\qquad L_{m}, \mathrm{~cm}\right)\end{array}$ & $\begin{array}{l}L_{m}=0.57 L^{1.034}=0.011 \\
\quad( \pm 0.02)\end{array}$ & 0.997 \\
\hline
\end{tabular}

Values in parentheses are \pm 2 SE. Total length $=\mathrm{L}$. cm. Sample size $=19$.

electrodes were inserted into the myotome at $1 \mathrm{~cm}$ intervals, and contraction of the whole myotome was elicited by a $10 \mathrm{~ms} 10 \mathrm{~V} \cdot \mathrm{cm}^{-1} \mathrm{dc}$ electric stimulus. This stimulus was previously determined to be the minimum stimulus giving the maximum motor response. Contraction of the myotome lifted weights close to the fulcrum of the beam. Adjustable stops limited the excursion of the beam to 1 $\mathrm{cm}$. An isotonic myograph transducer was attached to the beam to measure lateral tail velocities normal to the surface. Displacements were displayed on a storage oscilloscope and a physiograph, and stored on tape. Shortening speeds were measured for at least ten loads ranging from close to zero to the maximum that was justed lifted. Tests were made no more frequently than every 30 seconds, and results from fatigued muscle were not included in the analysis.

At the end of an experiment, the length of the myotome was measured from the cleithrum to the base of the hypural complex. Tracings were made of the muscle cross section at 10 equal intervals along the myotome, from which the average muscle cross-sectional area was measured. All muscle was dissected from the skeleton and skin and weighed. These relationships are summarized in Table 1.

\section{Results}

As previously found for this preparation, Hill's equation did not provide a good description of the 

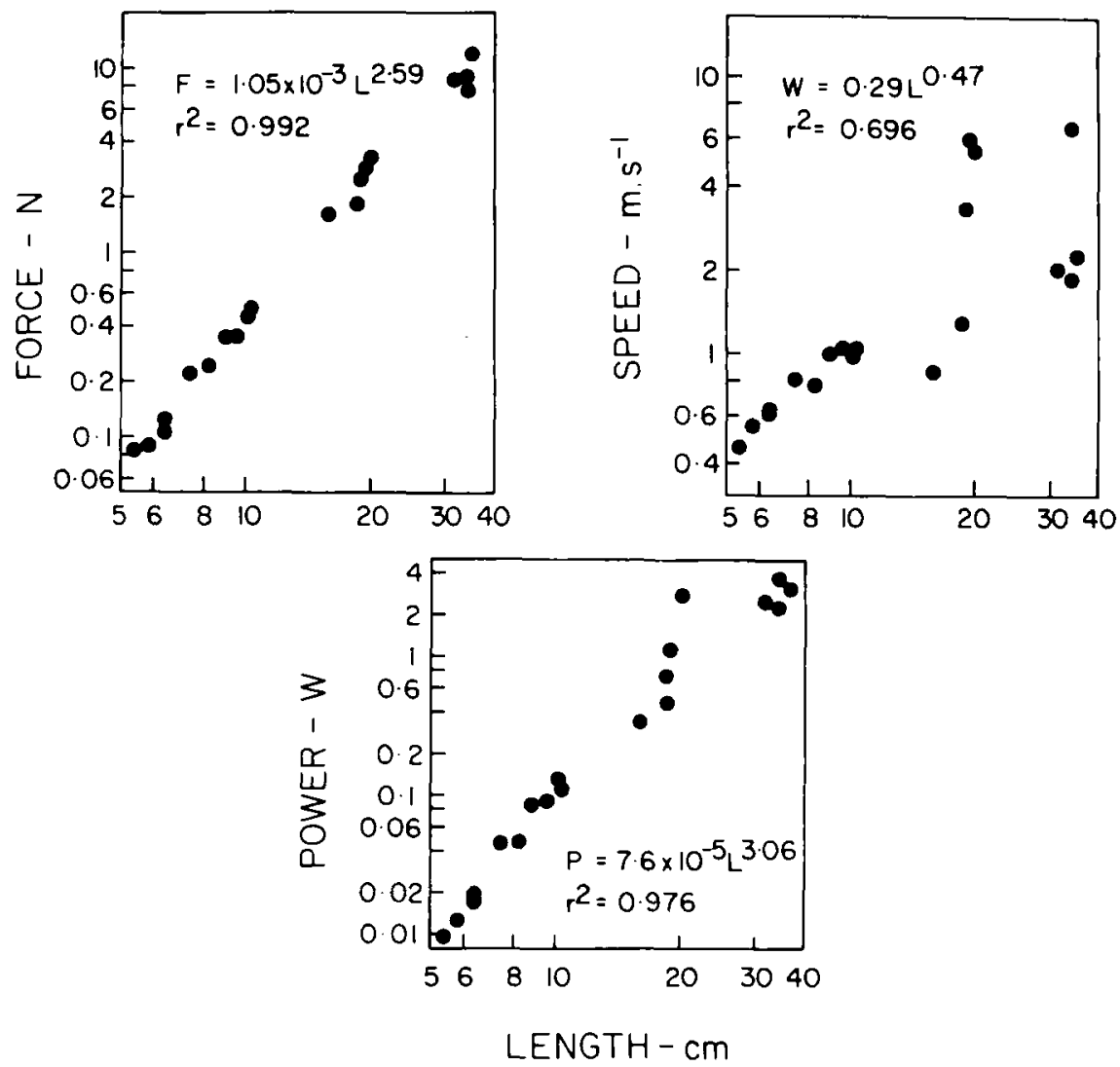

Fig. 1. Relationships between maximum normal force $(F)$, maximum lateral velocity (W) and maximum power ( $P$ ) measured at (he hypural complex of rainbow trout and total length (L).

force-velocity relationship, this being attributable to the complex geometry of the muscle-skeletal system of the intact myotome (Johnsrude and Webb 1985). Instead, simple linear regression was found to give the best description of the relationship between the force generated by the half-myotome preparation and the lateral velocity, both measured at the hypural plate. Therefore, only maximum force (at zero shortening velocity) and maximum velocity (at zero force) are reported since these define the limits of the relationship between force and lateral velocity for the tail. Maximum power was calculated from the regression relationships between force and velocity. All these measures of muscle performance increased with fish size (Fig. 1).

Muscle mass and power increased with length ( $\mathrm{L}$, $\mathrm{cm})$ at similar rates $\left(\mathrm{L}^{3.14}\right.$ and $\mathrm{L}^{3.06}$ respectively, Table 1 and Fig. 1). Consequently, mass specific power (power - muscle mass ${ }^{-1}$ ) was independent of size, with a value of $40 \mathrm{~W} \cdot \mathrm{kg}^{-1}$ for an average fish $20 \mathrm{~cm}$ in length. In contrast, average specific force (maximum force per unit area of the half myotome, $\sigma \mathrm{kN} \cdot \mathrm{m}^{-2}$ ) was related to fish length as:

$$
\sigma=9.6 \mathrm{~L}^{0.80} \quad \mathrm{r}^{2}=0.896
$$

For a $20 \mathrm{~cm}$ fish, $\sigma$ was $104 \mathrm{kN} \cdot \mathrm{m}^{-2}$. Typical maximum power output and stresses for teleost fast glycolytic (Type IIb; white muscle) fibers are 80 $\mathrm{W} \cdot \mathrm{kg}^{-1}$ and 40 to $186 \mathrm{kN} \cdot \mathrm{m}^{-2}$ (Bainbridge 1961; Flitney and Johnston 1979; Altringham and Johnston 1982; Johnston and Salmonski 1984; Moerland and Sidell 1986). The difference between these measures of performance for isolated muscle fibers versus the half-myotomal preparation are attributed to losses due to the geometry of the myotome (Johnsrude and Webb 1985). 


\section{Discussion}

Scaling of myotome size .

A variety of models, based on geometric, elastic or kinematic similarity have been used as hypotheses to explain scaling of structures and performance of organisms and their component systems. These models provide convenient references for examining size-related phenomena. Only geometric and elastic similarity are applicable to aquatic organisms, where gravity is not a major factor in locomotion. Elastic similarity models, although usually used to analyze animals under gravitational loads, are relevant to aquatic animals. The basic principles of the model relate to failure in buckling, which can occur as a result of forces applied to the skeleton by muscles such as the myotome, as well as by gravity.

Length is the characteristic measure of size for fish because it is the scale measure for Reynolds number (Bainbridge 1961; Hoerner 1965; Alexander 1967; Webb 1975; Blake 1983). Reynolds number indicates relative magnitudes of viscous and inertial resistance components, and likely flow patterns.

If dimensions change geometrically with size, then myotomal length would be proportional to $\mathrm{L}$ and muscle area to $\mathrm{L}^{2}$. Myotome length would scale'in the same way if animals were elastically similar, but area would scale with $\mathrm{L}^{3}$. This is because the fundamental premise in elastic similarity derives from the requirement that skeletal elements ultimately fail in buckling, which, from engineering practice requires diameter to vary with $\mathrm{L}^{3 / 2}$ (McMahon, 1973; 1984). Then, since area is proportional to diameter ${ }^{2}$, area is also proportional to $L^{3}$. In general, intraspecific scale effects are often closer to geometric similarity, while interspecific comparisons tend more towards elastic similarity (Alexander 1985). The same pattern was observed for the trout used here, as mean myotome length was proportional to fish total length while the cross-sectional area of the myotome scaled with $\mathrm{L}^{1.8}$ (Table 1), close to geometric similarity.

\section{Myolome performance}

The maximum force exerted by a muscle is determined by the number of contractile elements in parallel, and this is proportional to muscle area. However, the maximum force developed by the half-myotome preparation scaled with $\mathrm{L}^{2.6}$ (Fig. 1) not with area proportional to $\mathrm{L}^{1.8}$. Such a deviation from area dependence for force could be due to reductions in the amount of non-contractile tissue in parallel with muscle fibers, such as connective tissue, mitochondria and blood vessels, or changes in the geometry of the myotomal muscleseptum-vertebra-skin system (Wainwright 1983). However, data are lacking to evaluate these possibilities.

The shortening velocity of muscle is generally independent of size (McMahon 1984; SchmidtNielson 1984). Again, the half-myotome preparation did not follow the pattern seen in simpler muscle preparations, and instead lateral velocities increased with $\mathrm{L}^{0.47}$ (Fig. 1). Since the length of the myotome was essentially proportional to fish length (Table 1), the increase in velocity with size must relate to the period of myotomal twitch. This could be varied by; (a) size dependent variations in isoforms of myosin affecting rates of ATP splitting, analogous to the scaling of glycolytic enzyme activity in fish muscle (Somero and Childress 1980); (b) larger numbers of sarcomeres in series in larger fish; (c) changes in the fine-scale geometry to allow longer path lengths for fiber trajectories (Alexander 1969).

Irrespective of the basis for observed size effect on lateral velocities of the tail for the half-myotome preparation, the result is consistent with observations on locomotion of intact fish (Table 3). A variety of studies show that maximum amplitudes of locomotor movements are proportional to length while the period of propulsor movements is proportional to $L$ raised to a power varying from 0.2 to 1 , but averaging about 0.5 (Table 3 ). Under these circumstances, lateral velocities should scale with length to a power of about 0.5 , as observed for lateral tail speeds of the half-myotome preparation.

Power output of a muscle is the product of force and shortening speed, here proportional to $\mathrm{L}^{3.06}$ 
Table 2. Best fit linear regression equations describing scale relationships for the performance of the half-myotomal preparation shown in Fig. 1.

\begin{tabular}{|c|c|c|}
\hline & Equations & $r^{2}$ \\
\hline Force $(N)=$ & $\begin{array}{l}\left(.05 \times 10^{-3} \mathrm{~L}^{2.96( \pm 0.06)}\right. \\
\left( \pm 7.98 \times 10^{-4}\right)\end{array}$ & 0.992 \\
\hline Speed $\left(m \cdot s^{-1}\right)=$ & $\begin{array}{l}0.29 \mathrm{~L}^{0.47( \pm 0.04)} \\
( \pm 0.004)\end{array}$ & 0.696 \\
\hline Power $(W)=$ & $\begin{array}{l}7.6 \times 10^{-5} \mathrm{~L}^{3.06( \pm 0.12)} \\
\left( \pm 4 \times 10^{-5}\right)\end{array}$ & 0.976 \\
\hline
\end{tabular}

Values in parentheses are $\pm 2 S E$. Total length $=\mathrm{L}, \mathrm{cm}$. Sample size $=19$.

(Fig. 1), similar to expectations based on the properties of other excised vertebrate muscle. The elastic scaling model predicts muscle power should scale with $\mathrm{L}^{3}$. However, since areas and velocities do not scale as expected in the elastic similarity model, the agreement is purely coincidental.

\section{Swimming performance}

The twitch time for a muscle to complete a single contraction usually has been presumed to set ultimate limits on locomotor performance (Wardle 1975; Brill and Dizon 1979; Marsh and Bennett 1986a, b). On this basis, maximum swimming speed is given by SL/2T, where SL is stride length (the distance travelled in a complete tail beat, or two twitches) and $T$ is the twitch time (Wardle 1975).

In practice, there are difficulties with this attractively simple method, especially for fish. First, it is not known how muscle contraction translates into lateral movements for a system as complex as that of the fish myotome. Second, minimum twitch times are only meaningful if the amplitude of twitch is unaffected by load; in practice, as load increases this amplitude must decrease (Johnsrude and Webb 1985). However, tail beat amplitudes are large and do not decrease with performance level (Bainbridge 1958; Webb 1976). Therefore, travelling the large lateral distance executed by the tail under large loads at maximum performance levels may not be compatible with minimum twitch times.

Tail beat periods longer than expected minimum twitch times are observed during fast starts (Webb 1978). Unfortunately, there are no adequate data for sprints; Bainbridge's (1958) results for maximum tail beat frequency and speed must be viewed with caution because experiments were performed in a circular, small radius "fish wheel", with a narrow fish channel. Such designs may substantially affect the force balance due to ground (wall) effects on the caudal fin and from centrifugal resistance (Weihs 1980; Blake 1983). Bainbridge's subsequent experiments using a larger fish wheel only report

Table 3. Comparison of some scaling relationships for muscle and for swimming of fish. Lateral velocities, shown in parentheses are calculated from $W=a / T$, assuming that amplitude, $a$, is proportional to length where there are no data.

\begin{tabular}{|c|c|c|c|c|}
\hline Species & $\begin{array}{l}\text { Lateral velocity of } \\
\text { tail, } W\left(\mathrm{~cm} \cdot s^{-1}\right)\end{array}$ & $\begin{array}{l}\text { Period } \\
T(s)\end{array}$ & $\begin{array}{l}\text { Amplitude } \\
a(\mathrm{~cm})\end{array}$ & Source \\
\hline \multicolumn{5}{|l|}{ Expected from } \\
\hline $\begin{array}{l}\text { similarity } \\
\text { arguments }\end{array}$ & $L^{0}$ & $L^{\prime}$ & $L^{\prime}$ & Schmidt-Nielson (1984) \\
\hline \multicolumn{5}{|l|}{ Fish muscle } \\
\hline Salmo gairdneri & $\mathrm{L}^{0.47}$ & - & - & This study \\
\hline Four marine species & $\left(L^{0.6}\right)$ & $\mathrm{L}^{0.4}$ & - & Wardle (1975) \\
\hline \multicolumn{5}{|l|}{ Fast-starts } \\
\hline Salmo gairdneri & $\left(L^{0.72}\right)$ & $\mathrm{L}^{0.28}$ & - & Webb (1976) \\
\hline $\begin{array}{l}\text { Seven freshwater } \\
\text { species }\end{array}$ & $\left(\mathrm{L}^{0}\right)$ & $L^{1}$ & $L^{\prime}$ & Webb (1978) \\
\hline \multicolumn{5}{|l|}{ Sprint swimming } \\
\hline Salmo gairdneri & $\left(\mathrm{L}^{0.72}\right)$ & $\mathrm{L}^{0.18}$ & $L^{\prime}$ & Bainbridge (1958) \\
\hline \multicolumn{5}{|c|}{ Critical swimming speed } \\
\hline Salmo gairdneri & $\left(\mathrm{L}^{0.05}\right)$ & $L^{0.69}$ & $\mathrm{~L}^{0.74}$ & Webb et al. (1984) \\
\hline
\end{tabular}


sprints lasting one second or longer which probably underestimates maximum sprint speed. Wardle (1975) reports a single $10 \mathrm{~cm}$ haddock (Melanogrammus aeglefinus) swimming at $260 \mathrm{~cm} \cdot \mathrm{s}^{-1}$, with a total beat period similar to minimum twitch times. However, it is not known if the speed is typical for fish of this size and species.

Johnsrude and Webb (1985) used the half-myotome preparation to retain essentially normal muscular-skeletal links, to avoid the problems of uncertain extrapolation from excised muscle to locomotor movements, and to base calculations of performance limits on a wider set of mechanical properties than twitch time. However, they continue to assume maximum swimming performance is limited by myotomal-skeletal mechanics of single twitches.

Using the same approach for the half-myotome preparations from trout of a range of sizes, expected swimming performance is most conveniently determined from the relationships between force and lateral speed at the tail of the preparation. Maximum acceleration rate occurs at the beginning of a fast start, and should be determined by the maximum force of the preparation, corrected by a factor of about 0.5 for the difference between the path of the center of mass and the force vector of the tail (Johnsrude and Webb 1985). Alternatively, maximum. swimming speed should be obtained where the speed possible for a given tail beat frequency is equal to that possible for a given thrust; i.e. at the intersection of speeds predicted (a) for the thrust force of the preparation and (b) from the lateral speed of the tail expected from the preparation. Tail beat frequency is obtained as the lateral speed of the tail (hypural complex) divided by the distance travelled by the tail in one beat. The latter is twice the tail beat amplitude, taking values of $0.2 \mathrm{~L}$ (see Bainbridge 1958, 1963; Hunter and Zweifel 1971). The swimming speed possible for a given tail beat frequency is calculated as the product of stride length and tail beat frequency (Wardle 1975). The speed possible for a given force is determined by solving the equations for drag for swimming speed (Fig. 2) as described in detail by Bainbridge (1961), but adjusted for the effects of swimming movements on drag coefficients (Alexander 1967; Webb
1975; Blake 1983; Johnsrude and Webb 1985).

Before calculating speeds expected from data on myotomal contractions, however, it must be recognized that performance will be affected by body proportions and muscle masses which vary markedly within species and among species. For example, muscle mass varies from $30 \%$ of the body mass in sculpin, Cottus cognatus (Webb 1978a), to 60\% in thunnids (Dotson 1978). For rainbow trout, the myotome of healthy fish typically represents about $50 \%$ of the body mass, but ranges from as little as $40 \%$ (Table 1) to $65 \%$ (Bainbridge 1962). Therefore, the most useful results from this study are the size specific measures of the thrust generating capability of the myotome. These can be used to consider swimming performance for fishes with a variety of muscle masses, and this is incorporated into the calculations described below and in Fig. 2.

Typical predicted and reported maximum acceleration rates and swimming speeds are shown in Fig. 2. Predicted maximum speeds based on minimum twitch times from excised muscle blocks (Wardle 1975) are also shown. Three points emerge from these calculations: First, predicted maximum speeds based on the mechanical properties of the myotome typically are lower than those predicted from minimum twitch of times. Second, predicted maximum acceleration rates typically are lower than observed. Third, there is a size effect in that as size increases so do differences between; (a) maximum swimming speeds determined from minimum twitch times of excised muscle and from the properties of the half-myotome preparation and (b) observed and predicted acceleration rates. Similar conclusions result from performance calculations based on other mechanical properties of the preparation, such as work or power.

All the results of calculations in Fig. 2 are predicted, as usual (e.g. Wardle 1975) on the assumption that periods of single twitches determine maximum performance. Instead, it appears probable that twitch times limit performance only in small fish. The times to complete one tail movement based on the mechanical performance of the half-myotome increasingly diverge from the minimum twitch times measured by Wardle (1975). Thus for $5 \mathrm{~cm}$ fish, the period for half of a tail beat 

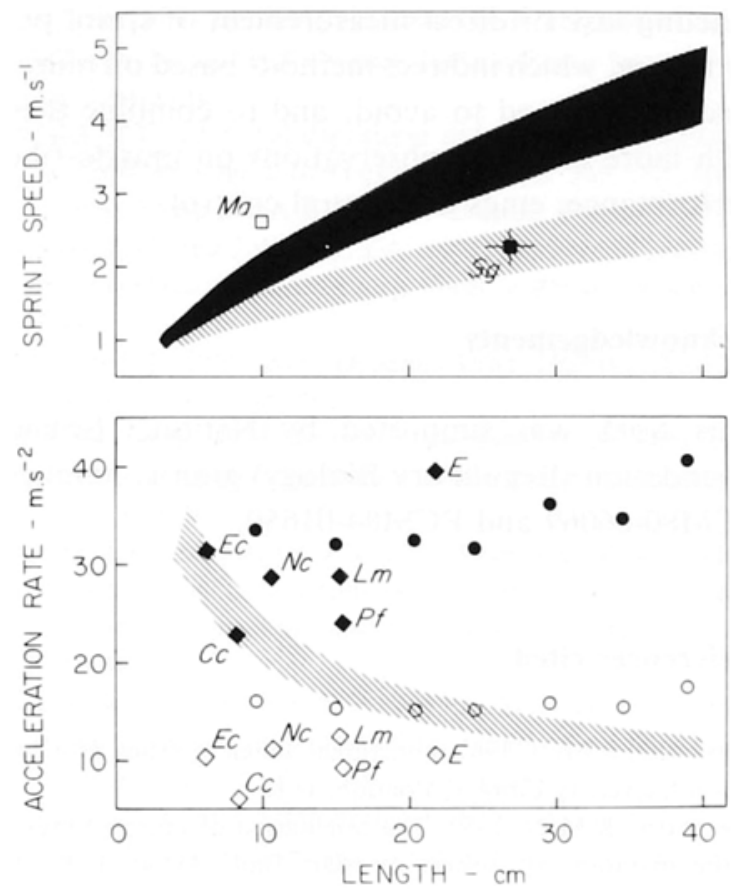

Fig. 2. (a) Maximum sprint swimming performance predicted for the half-myotome preparation (cross hatched) are for speeds at the intersection point of those determined for force and from lateral tail speeds. The former are shown only for fully turbulent boundary layer conditions, probably a conservative solution, when swimming speed, $u(c m \cdot s * 1)$ is given by: $u=$ $[\mathrm{F} / 0.057 . \mathrm{L}-0.2 . \mathrm{A}]^{1 / 18} \mathrm{~S}\left(\mathrm{~cm}^{2}\right)$ is the total weted surface area and $S=0.28 . L^{2.11}$ (Webb 1977). Lower and upper boundaries are results for lish with 40 and $50 \%$ muscle respecively. $F(N)$ is calculated from the data in Fig. 1 for the muscle area given by equations in Table 1. To accommodate the effect of different proportions of muscle for fish of a given length, myotome length was assumed constant (Table 1), when thanges in cross-sectional area and $\mathrm{F}$ are directly proportional to the ratio of the muscle mass used in calculations $(40$ or $50 \%$ ) and measured for the preparation (Table 1).

Sprint speeds calculated from minimum twitch times given by Wardle (1975) are shown (solid), with lower and upper boundaries for stride lengths of $0.7 \mathrm{~L}$ and $0.9 \mathrm{~L}$ respectively. Further details are given in the text.

(b) Maximum acceleration rates (cross hatched) predicted from the forces developed by the half-myotome preparation. and various measured values. Closed symbols are maximum acceleration rates and open symbols mean acceleration rates through stages one and two of a fast start.

Key; solid square and $S g$; one second sprints of eight trout, Salmo gairdneri from Bainbridge (1962). Vertical and horizontal bars show wo standard errors about the mean. Open square and Ma; a single haddock, Melanogrammus aeglefinus from Wardle (1975). Solid circles; maximum acceleration rates for rainbow is about $38 \mathrm{~ms}$ compared to $31 \mathrm{~ms}$ from Wardle (1975); the former time was obtained from the maximum lateral speed of the tail for the preparation traveling through a distance of $0.2 \mathrm{~L}$, the typical maximum amplitude of the tail of swimming fish (Hunter and Zweifel 1971). At $40 \mathrm{~cm}$ these periods are 130 and $71 \mathrm{~ms}$ respectively. Similarly, measurements of half tail-beat periods in fast starts are at least twice the minimum twitch times (Webb 1978). As a result, there is opportunity for temporal summation of post synaptic potentials. Force is well known to attain substantially larger values under these conditions (up to a maximum in tetanus), and summation could provide more that sufficient force to accelerate fish at observed maximal rates (McMahon 1984). Sprint speeds also would be increased if there were summation of twitches, but these would be modest compared to the changes in force. This is because swimming speed is presumed to depend on a balance between contraction velocity and force, which are inversely related.

Some factor in addition to the mechanical properties of twitches alone is required to explain observed size relationships of swimming performance. Furthermore, such additional factors would appear necessary for other muscle systems. Thus, the muscle force and hence the acceleration rate of the system they power is usually expected to increase in proportion to the muscle cross-sectional area, $\mathrm{L}^{2}$. However, inertial effects that dominate resistance in fitness-critical, survival maneuvers increase with $\mathrm{L}^{3}$, sq that acceleration should vary with $\mathrm{L}^{-1}$ (Daniel and Webb 1987). Acceleration behaviors underly much of prey capture and predator avoidance (Weihs and Webb 1983) and acceleration is a necessary precursor to attaining any speed. It is not surprisingly, therefore, that acceleration rates actually are often independent of size (Webb 1976,1978 ), when the mechanics of single twitches are inadequate to explain the relationship.

trout from Webb (1976); open circles, mean accelerations rates from the same source. Closed diamonds and open diamonds are maximum and mean acceleration rates from Webb (1978a) for; Ec; Etheostoma cueruleum; Ca; Cottus cognatus; Nc, Notropis cormutus; Lm, Lepomis macrochirus; $\mathrm{Pf}$, Perca flavescens; E. Esox species. 
The acceleration requirements of fish over a wide size range could be met if muscle cross-sectional area increased in proportion to mass. This is, of course, the conclusion from elastic similarity (McMahon 1973), but, as Alexander (1985) points out, such scaling patterns cannot be maintained over large size ranges. Furthermore, individuals within species tend towards isometry, as observed for trout (Table 1). Trout partially overcome the imbalance between muscle forces normally proportional to $\mathrm{L}^{2}$ versus inertial loads proportional to $\mathrm{L}^{3}$ in some unknown way, since $\sigma$ for the myotomemuscle complex is not constant, but increases with size (Fig. 1). Nevertheless, the muscle forces still are not proportional to body mass. Thus, the only other option for matching forces with body inertia appears to be modification of propulsor periods (frequency) to increase force in larger fish, as suggested above.

A change in the factors that limit maximum swimming performance, from muscle mechanical properties in small fish to postulated neuromuscular properties in large fish may explain some features of predator-prey interactions. Howland (1974), Webb (1976) and Somero and Childress (1980) have pointed out that the ability of aquatic predators to chase down prey would be reduced if sprint performance followed the scaling relationships established for aerobic tissues. Therefore, the postulated dependence of sprint swimming of large fish on summation of a few twitches rather than on single twitches may be necessary to provide increased thrust and power. However, prey success in avoiding predation appears to be more dependent on timing and the rapid completion of the initially stereotyped stages of the startle response (Webb 1986; Nissanov and Eaton 1987). Thus the initial displacement of small fish and completion of the first beat of the startle response in a short time may be most important, and these would be achieved by single myotomal twitches.

This discussion indicates that understanding the limits of motor performance probably cannot be adequately based solely on muscle mechanics data. For example, it is postulated that neural control plays a major part in determining maximum swimming performance. It seems essential to solve the exacting task of direct measurement of sprint performance, which indirect methods based on muscle mechanics hoped to avoid, and to combine these with more complete observations on muscle fiber performance, emgs and neural control.

\section{Acknowledgements}

This work was supported by National Science Foundation (Regulatory Biology) grants, numbers PCM80-06069 and PCM84-01650.

\section{References cited}

Alexander, R.McN. 1967. Functional design in fishes. Hutchinson University Library, London, U.K.

Alexander, R.McN. 1969. The orientation of muscle fibres in the myotome of fishes. J. Mar. Biol. Assoc. U,K. 49: 263-290

Alexander, R.McN, 1985. Body support, scaling and allometry. In Functional Vertebrate Morphology. pp. 26-37. Edited by M. Hildebrand, D.M. Bramble, K.F. Liem and D.B. Wake. Harvard University Press, Cambridge, MA.

Altringham, J.D. and Johnston, I.A. 1982. The pCa-tension and force-velocity characteristics of skinned fibres from fish fast and slow muscles. J. Physiol. 333: 421-449.

Bainbridge, R. 1958. The speed of swimming of fish as related to size and to the frequency and amplitudes of the tail beat. J. Exp. Biol. 35: 109-133.

Bainbridge, R. 1961. Problems of fish locomotion. Symp. Zool. Soc. Lond. 5: 13-32.

Bainbridge, R. 1962. Training speed and stamina in trout. J. Exp. Biol. 35: 134-137.

Bainbridge, R. 1963. Caudal fin and body movements in the propulsion of some fish. J. Exp. Biol. 40: 23-56.

Blake, R.W. 1983. Fish Locomotion. Cambridge University Press, Cambridge, U.K.

Bretl, J.R. 1965. The relation of size to the rate of oxygen consumption and suslained swimming speed of sockeye salmon (Oncorhynchus nerka). J. Fish. Res. Board Can. 22: L.149!-1501.

Brett, J.R. and Glass, N.R. 1973. Metabolic rate and critical swimming speeds of sockeye salmon (Oncorhynchus nerka) during sustained performance. J. Fish. Res. Board Can. 30: 379-387.

Brill, R.W. 1978. Temperature effects on speed of muscle contraction and stasis metabolic rate. In The Physiological Ecology of Tunas. pp. 277-283. Edited by G.D. Sharp and A.E. Dizon. Academic Press, New York.

Daniel, T. and Webb, P.W. 1987. Physics, design and locomotor performance. In Comparative Physiology: Life in Water 
and on Land. pp. 343-369. Edited by P. Dejours, L. Bolis, C.R. Taylor and E.R. Weibel. Liviana Press, Springer-Verlag, New York.

Dotson, R.C. 1978. Fat deposition and utilization in albacore. In The Physiological Ecology of Tunas. pp. 343-355. Edited by G.D. Sharp and A.E. Dizon. Academic Press, New York.

Fliney, F.W. and Johnston, I.A. 1979. Mechanical properties of isolated red and white muscle fibres. J. Physiol. Lond. 295: 49-60.

Hoerner, S.F. 1965. Fluid-Dynamic Drag. Hoerner Fluid Dynamics, Brick Town, N.J.

Howland, H.C. 1974. Optimal strategies for predator avoidance: The relative importance of speed maneuverability. J. Theor. Biol. 47: 333-350.

Hunter, J.R. and Zweifel, J.R. 1971. Swimming speed, tail beat frequency, tail beat amplitude and size in jack mackerel, Trachurus s.mmetricus, and other fishes. Fish Bull. U.S. 69 : 253-266

Johnsrude, C.L and Webb, P.W. 1985. Mechanical properties of the myotomal musculo-skeletal system of rainbow trout, Salmo gairdneri. J. Exp. Biol. 119: 71-83.

Johnston, I.A. and Salamonski, J. 1979. Power output and force-velocity relationship of red and white muscle fibres from the Pacific blue marlin (Makaira nigrans). J. Exp. Biol. 111: 171-177.

Marsh, R.L.and Bennell, A.F. 1986a. Thermal dependence of contractile properties of skeletal muscle from the lizard Sceloporus occidentalis with comments on methods for fitting and comparing force-velocity curves. J. Exp. Biol. 126: 63-77.

Marsh, R.L. and Bennetl, A.F. 1986b. Thermal dependence of sprint performance of the lizard Sceloporus occidentalis. J. Exp. Biol. 126: 79-87.

McMahon. T.A. 1977. Size and shape in biology. Science 179: $1201-1204$.

McMahon. T.A. 1984. Muscles, Reflexes and Locomotion. Princeton Univ. Press, Princeton, NJ.

Moerland, T.S. and Sidell, B.D. 1986. Biochemical responses to temperature in the contractile protein complex of striped bass Morone saxilis. J. Exp. Zool. 238: 287-295.
Nissanov, R.J. and Eaton, R.C. 1987. Reticulospinal control of rapid escape curning maneuvers in fishes. Amer. Zool. (in press).

Schmidt-Nielson, K. 1984. Scaling: Why is Animal Size so Important? Cambridge Univ. Press, Cambridge, U.K.

Somero, G.N. and Childress, J.J. 1980. A violation of the metabolism-size scaling paradigm: Activities of glycolytic enzymes in muscle increase in larger-size fish. Physiol. Zool. 53: $322-337$.

Wainwright, S.A. 1983. To bend a fish. In Fish Biomechanics. pp. 68-91. Edited by P.W. Webb and D. Weihs. Praeger, New York.

Wardle, C.S. 1975. Limil of fish swimming speed. Nature, Lond. 255: 725-727.

Wardle, C.S. 1977. Effects of size on the swimming speeds of fish. In Scale Effects in Animal Locomotion. pp. 299-313. Edited by T.J. Pedley Academic Press, New York.

Webb, P.W. 1975. Hydrodynamics and energetics of fish propulsion. Bull. Fish. Res. Board Canada 190: 1-159.

Webb, P.W. 1976. The effect of size on the fast-start performance of rainbow trout (Salmo gairdneri) and a consideration of piscivorous predator-prey interactions. J. Exp. Biol. 65: 157-177.

Webb, P.W. 1977. Effects of size on performance and energetics of fish. In Scale Effects in Animal Locomotion. pp. 315-331. Edited by T.J. Pedley. Academic Press, New York.

Webb, P.W. 1978a. Fast-start performance and body form in seven species of teleost fish. J. Exp. Biol. 74: 211-216.

Webb, P.W. 1978b. Temperature effects on acceleration of rainbow trout Salmo gairdneri. J. Fish Res. Board Canada 35: 1417-1422.

Webb, P.W., P.T. Kostecki and Stevens, E.D. 1984. The effect of size and swimming speed on locomotion kinematics of rainbow trout. J. Exp. Biol. 109: 77-95.

Weihs, D. 1981. Effects of swimming path curvature on the energetics of fish motion. Fish. Bull. U.S. 79: 171-176.

Weihs, D. and Webb, P.W. 1983. Optimization of locomotion. In Fish Biomechanics. pp. 339-37I. Edited by P.W. Webb and D. Weihs. Paegèr, New York. 